\title{
ENGENHARIA ELÉTRICA E SEGURANÇA DO TRABALHO: O USO DOS EQUIPAMENTOS DE PROTEÇÃO INDIVIDUAL - EPI
}

*Lázzaro Henrique Soares Barbosa

\section{RESUMO}

Este artigo discute a importância do uso de equipamentos de proteção individual (EPI) para prevenção de acidentes de trabalho no campo da energia elétrica. $O$ método utilizado foi a pesquisa de abordagem qualitativa, descritiva. As fontes de pesquisa são todas aquelas admitidas na pesquisa em Engenharia, Segurança do Trabalho e Saúde, com livros de autores que versem sobre o tema, sites e periódicos, revistas. Os resultados encontrados apontam que a maioria dos empregados e empregadores reconhecem a importância do uso de equipamentos de proteção individual adequados aos riscos presentes no ambiente de trabalho, porém, a falta ou o uso inadequado podem ter favorecido a ocorrência de acidentes ocupacionais. As considerações finais apontam a necessidade de empregadores e empregados do ramo da engenharia elétrica investir na capacitação e treinamento dos trabalhadores para o uso adequado dos equipamentos de proteção individual de forma a possibilitar um ambiente de trabalho mais seguro.

Palavras-chave: EPI. Prevenção de Acidentes. Engenharia Elétrica

\section{ABSTRACT}

This article discusses the importance of using personal protective equipment (PPE) to prevent accidents at work in the field of electrical energy. The method used for a qualitative, descriptive research. The research sources are all those admitted to research in Engineering, Workplace Safety and Health, with books by authors dealing with the theme, websites and journals, magazines. The results found point out that most employees and employers recognize the importance of using personal protective equipment appropriate to the risks present in the work environment, however, the lack or incorrect use may have favored the occurrence of occupational accidents. Final considerations point to the need for employers and employees in the electrical engineering sector to invest in the training and 
training of workers in the proper use of personal protective equipment in order to enable a safer work environment.

Keywords: PPE. Accidents prevention. Electrical engineering

*Lázzaro Henrique Soares Barbosa é aluno do 7‥ Semestre em Engenharia Elétrica pelo Instituo Federal da Bahia (IFBA).

\section{INTRODUÇÃO}

O contexto trabalhista contemporâneo do ramo da engenharia ressalta a importância do uso dos EPl's (equipamentos de proteção individual), isso se evidencia pela necessidade de garantir a todos trabalhadores a segurança contra possíveis riscos ameaçadores da saúde ou segurança dos mesmos durante as determinadas atividades.

No Brasil em razão do constante crescimento populacional, aliado a concentração da população em áreas urbanas, gera automaticamente uma alta demanda na construção de infraestrutura e habitação para todos, gerando aproximadamente 10 milhões de empregos dos quais $69 \%$ ligados diretamente a canteiros de obras. (BRASIL, 2019).

O Ministério Público do Trabalho registrou 4.083.397 comunicações de acidente de trabalho no Brasil. Segundo o site do Observatório Digital de Saúde e Segurança no Trabalho, dentre esses acidentes 21,03\% resultaram em cortes e lacerações, $17,50 \%$ em fratura, $15,74 \%$ em contusão ou esmagamento e $1,12 \%$ em amputação ou enucleação. Consequentemente, é possível observar o aumento de acidentes, dados apontam que todos os anos acontecem cerca de 4.098 acidentes fatais num total de 4.104 ocorrências. (Observatório Digital de Saúde e Segurança do Trabalho, 2020).

Deve-se levar em conta, ainda, que estes números não refletem a globalidade total de acidentes, pois, os especialistas em segurança no trabalho 
acreditam que apenas $50 \%$ dos acidentes de trabalho são registrados oficialmente. Baseado nesses números alarmantes, criou-se uma norma regulamentadora, a NR 6, que é uma norma determinada pelo Ministério do Trabalho que deve ser seguida à risca em todos os empreendimentos, independente do porte, o objetivo é estabelecer regras claras, para assim poder evitar acidentes e danos à saúde do trabalhador. (BOZZA, 2010).

Os constantes riscos referentes aos acidentes especialmente na área da eletricidade são presentes, e necessitam ser combatidos por meio da preservação, na qual se faz por diferentes formas, principalmente através de treinamentos, qualificação, fiscalização, e essencialmente 0 uso dos Equipamentos de Proteção Individual. Não pode existir qualidade onde há insegurança, é inconcebível pensar que um trabalhador possa desempenhar de maneira satisfatória, suas funções, em um ambiente que não inspira segurança.

Contudo visto, por falta de orientação ao uso dos equipamentos de segurança, em destaque nas atividades da área elétrica que se caracteriza por ser uma área que está em constante crescimento no decorrer do tempo, com inovações tecnológicas, capazes de facilitar e tornar as soluções mais rápidas, e fáceis de serem executadas em termos de fornecimento de energia.

Outrossim, é de extrema importância que se tenha estratégias para proteger os profissionais, a prioridade de ter a eliminação e o controle de riscos entre a função e trabalhador. Um risco não pode ser eliminado pelo uso do EPI, mas o risco de lesão pode ser descartado ou reduzido.

Porém, enquanto os empresários não se conscientizarem do grave problema de acidentes no trabalho, nenhum esforço obterá sucesso. Como muitos empresários "pensam" em termos de custos, deveriam saber que um Programa Integral de Segurança, com o objetivo de atuar preventivamente e, consequentemente, contribuir para evitar acidentes, acarretaria uma diminuição de custos, pois, um acidente no trabalho causa custos muito maiores, e o que se nota é que nem mesmo as exigências legais são cumpridas. 
Entende-se que o bem-estar, a saúde e a segurança é preponderante no contexto trabalhista, a determinação desse tema deve-se a importância de levar aos conhecimentos das pessoas que exercem atividades em lugares determinado anteriormente, os riscos que acarreta quando não se faz o uso de dispositivos de segurança, que pode estar associado pela má administração ou falta de instrução dos operários.

Nesse contexto, surge o seguinte problema: como o empregador da área da eletricidade, pode atuar em sua empresa no sentido que haja uma conscientização da importância e da obrigatoriedade do uso de Equipamentos de Proteção individual aos seus funcionários?

Assim, objetivou-se através do presente trabalho caracterizar acidente e EPI, caracterizar as principais ações de conscientização na área de segurança no trabalho na construção civil, através de pesquisa bibliográfica, abordando a necessidade do uso de Equipamentos de Proteção Individual (EPI), com origem a importância e aplicação nos ambientes de trabalho e canteiros de obras.

\section{METODOLOGIA}

O trabalho foi realizado através de uma pesquisa bibliográfica seguindo a metodologia qualitativa e descritiva. A pesquisa bibliográfica segundo Gil (2002) é aquela que permite ao investigador a cobertura de uma gama de fenômenos muito mais ampla do que aquela que poderia pesquisar diretamente.

As fontes de pesquisa são todas aquelas admitidas na pesquisa em Engenharia Elétrica, Saúde do Trabalhador, Saúde, Eletricidade, Acidentes. Desde livros de autores que versem sobre o tema, até sites e periódicos, revistas. A leitura informativa científica procura reconhecer as informações sobre o tema em foco, vislumbrando a possibilidade de analisá-lo, relacioná-lo e compará-lo situando-o na delimitação em questão. 
A pesquisa foi realizada com a seleção de 10 artigos que foram prioritariamente pesquisados no SCIELO (Scientific Electronic Library Online) utilizando como palavras - chaves: EPI, acidentes, eletricidade, segurança e prevenção. Foram priorizados e incluídos artigos publicados após o ano 2000; artigos publicados em português; e artigos publicados na íntegra. Os critérios de exclusão foram: artigos em língua estrangeira e artigos com mais de 20 anos de publicação.

Os artigos foram lidos para a realização da revisão bibliográfica segundo as seguintes etapas: Leitura e identificação dos objetivos de cada texto; Identificação dos pontos relacionados à EPI em cada artigo; Leitura sistemática dos textos elaborando um fichamento de cada um; síntese dos elementos de cada artigo para montagem do trabalho final.

\section{RESULTADOS}

Para entender a importância dos EPI e da segurança no trabalho, precisase trabalhar com a definição desses termos e detectar sua importância no ambiente de trabalho e especificamente no ramo da construção civil. Para entender a importância do ramo da segurança do trabalho, é preciso entender primeiro a definição de acidente no trabalho.

\subsection{ACIDENTE DE TRABALHO}

Acidente do trabalho, é descrito por Ayres (2011) como aquele que ocorre pelo exercício laboral, a serviço da empresa, provocando lesão corporal, perturbação funcional doença que cause a morte, perda ou redução permanente ou temporária de condições para o trabalho.

Essa definição ratifica o que está disposto na lei Lei no 8.213/91, cujo artigo 19 define acidente de trabalho como aqueles que acontecem durante a execução de trabalho a serviço de uma empresa, provocando lesão corporal ou 
perturbação funcional que cause a morte, perda ou redução da capacidade do trabalhador. (BRASIL,1991).

Segundo Bozza (2010) também são considerados acidentes de trabalho aqueles o que ocorrem em situações externas, ou seja, quando o empregado estiver executando ordem ou realizando serviço sob o mando do empregador; os ocorridos viagens de serviço, os ocorridos em percurso residência/local de trabalho e vice-versa, os ocorridos nos períodos de descanso ou por ocasião da satisfação de necessidades fisiológicas, no local de trabalho, por contaminação acidental do empregado no exercício de sua atividade.

Dentro desta configuração os acidentes são classificados em típicos, ou seja, aqueles que ocorrem ou por violência ou por infortúnio, tais como batidas, quedas, choques, cortes, queimaduras, as doenças do trabalho que são alterações no organismo sofridas em decorrência de agentes externos aos quais o trabalhador esteja exposto tais como, ruído, calor, gases, vapores, microorganismos; os acidentes de trajeto sofrido pelo empregado no percurso da residência para o local de trabalho ou vice-versa, qualquer que seja o meio de locomoção, inclusive veículo de propriedade do empregado, em horários e trajetos compatíveis. (BOZZA, 2010).

Ainda para este autor, as principais consequências dos acidentes para os indivíduos são, além das lesões, incapacidade parcial ou permanente, afastamento do trabalho, diminuição do salário, dificuldades no sustento da família e até morte. Consequentemente isso gera também para a empresa, obstrução no tempo e na produção de bens e serviços, danos às máquinas, materiais ou equipamentos, despesas com primeiros socorros, despesas, com treinamento para substitutos, atraso na produção e aumento de preço no produto final. (BOZZA, 2010).

As principais causas de acidente de trabalho, como referidas anteriormente (doenças laborais, acidentes de trabalho ou de trajeto) são ocasionados por ato inseguro ou condições inseguras. Ato inseguro é entendido 
como aquele que provocado pelo ser humano e de maneira consciente ou não, provoca dano ao trabalhador, aos companheiros e às máquinas e equipamentos como por exemplo atos improvisados, fata de usos dos equipamentos de proteção individual (EPI), ação sem permissão ou supervisão, entende-se aqui que o empregado conhece os riscos a que está exposto e ainda assim arriscase a fazê-lo. (AYRES,2001).

E os atos inseguros que, segundo o mesmo autor são as condições que, presentes no ambiente de trabalho, comprometem a integridade física e/ou a saúde do trabalhador, bem como a segurança das instalações e dos equipamentos

\subsection{SEGURANÇA DO TRABALHO}

Dá-se o nome de Segurança do Trabalho à tecnologia ou ciência que busca proteger o trabalhador em seu local de trabalho, evitando ou minimizando acidentes de trabalho e doenças ocupacionais. Suas normas e regulamentações descritas como Serviço Especializado em Engenharia de Segurança e em Medicina do Trabalho (SESMT), que está regulamentado em uma portaria do Ministério do Trabalho e Emprego (MTE), Norma Regulamentadora no 4 (NR-4) e, portanto, na legislação trabalhista brasileira.

De acordo os dados da Organização Internacional do Trabalho, cerca 330 milhões de pessoas são vítimas de acidentes de trabalho anualmente em todo o mundo e surgem 160 milhões de novos casos de doenças ocupacionais. Ainda segundo essa organização, há o registro de mais de 2 milhões de mortes relacionadas aos acidentes de trabalho, das quais 1,574 milhão ocorreram por doenças ocupacionais, 355 mil por acidentes e 158 mil por acidentes de trajeto. (OIT, 2019).

Segundo dados estatísticos do Observatório de Segurança e Saúde no Trabalho com dados de 2020: 


\section{Quadro 1}

\subsection{3 .4055}

Acidentes de Trabalhadores com Carteira

Assinada Notificados desde 2012 (INSS)1

1 notificação a cada 49s

Fonte: Observatório Digital de Saúde e Segurança no Trabalho, 2020.

Quadro 2

20.875

Mortes de Trabalhadores com Carteira

Assinada Notificadas desde 2012 (INSS)2

1 morte a cada 3 h $43 m$ 42s

Fonte: Observatório Digital de Saúde e Segurança no Trabalho, 2020.

Quadro 3 Dias de Trabalho perdidos desde 2012

446.297 .6477

Dias de Trabalho Perdidos com

Afastamentos Acidentários desde 2012 (INSS)

Fonte: Observatório Digital de Saúde e Segurança no Trabalho, 2020.

Quadro 4 Gastos com afastamentos 
100.221 .328 .163

Gastos com Afastamentos

Acidentários desde 2012 (INSS)4

$\mathrm{R} \$ 1,00$ a cada $2 \mathrm{~ms}$

Fonte: Observatório Digital de Saúde e Segurança no Trabalho, 2020.

Quadro 5

3.139 .0088

Notificações no Sistema Nacional de

Agravos de Notificação (SINAN) desde 2012 (SUS)5

1 notificação a cada 2 m 19s

Fonte: Observatório Digital de Saúde e Segurança no Trabalho, 2020.

Esses dados são constantemente atualizados e ampliados em alguns casos a cada milésimo de segundo o que agrava ainda mais a situação do Brasil em casos de acidentes de trabalho.

\section{3 .3 SEGURANÇA NO TRABALHO NA ENGENHARIA ELÉTRICA}

Diferente de outros setores industriais que dependem das máquinas e equipamentos para a obtenção da qualidade dos produtos, a área elétrica possui características próprias, dentre elas se destaca o fato de depender quase exclusivamente da mão-de-obra humana para a realização do trabalho. Essa dependência da mão de obra deveria cooperar para que este fosse um setor mais desenvolvido em termos de segurança no trabalho, percebe-se porém que o percentual de acidentes e doenças ocupacionais aumentam a cada ano. 
Quadro 6 - Notificações de Acidente de Trabalho por Setor Econômico

\begin{tabular}{lrcr}
\hline Setor Econômico & Total & Smartline (2012-2018) & Pico \\
& & & \\
$\begin{array}{l}\text { Serviços de engenharia } \\
3.593 \text { (2013) }\end{array}$ & 19.366 & $3.443-2.145$ & \\
$\begin{aligned} \text { Obras de engenharia } \\
\text { civil não especificadas } \\
\text { anteriormente }\end{aligned}$ & 16.983 & $4.365-994$ & 4.365 (2012) \\
\hline
\end{tabular}

Fonte: Observatório Digital de Saúde e Segurança no Trabalho, 2020.

Os dados acima são parciais. Se forem colocados especificamente em termos de profissão ligadas à engenharia elétrica são bem mais amplos e refletem o panorama de insegurança e falta de conscientização e preparo de empregados e empregadores do setor.

Ainda assim, se empregador e empregado não seguirem à risca as regras de regulamentação dispostas nas leis, decretos e convenções internacionais e asseguradas pela Constituição Federal, Consolidação das Leis do Trabalho (CLT),

da Organização Internacional do Trabalho (OIT) e Organização Mundial da Saúde (OMS), a saúde e segurança do trabalhador estarão sempre em risco. (MANNRICH,1991).

Segundo Sousa (2019) quando se fala em eletricidade os 5 principais fatores que ocasionam acidentes são: Falta de treinamento técnico, o não seguimento dos procedimentos exigidos, a falta de comunicação, as distrações e o não uso dos EPIs. Para além dos problemas de energização acidental, explosões, descargas ou contato direto com redes energizadas. Essas outras principais causas de acidentes no trabalho nessa área não são tão específicas quanto um choque. 
A Norma Regulamentadora № 10 define perigo como situação ou condição de risco com probabilidade de causar lesão física ou dano à saúde das pessoas por ausência de medidas de controle. O documento define risco como capacidade de uma grandeza com potencial para causar lesões ou danos à saúde das pessoas. Em serviços com eletricidade, o trabalhador está exposto a riscos de acidentes com consequências diretas: choque e arco elétrico e com consequências indiretas: quedas, batidas, incêndio, explosões de origem elétrica, queimaduras etc. (CASTRO,2015).

Dentre os mais corriqueiros estão o choque elétrico, que conforme a tabela abaixo pode levar de simples formigamentos até à morte instantânea.

TABela 1 - Consequéncias do choove elétrico

\begin{tabular}{|c|c|}
\hline Intensidade da corrente elétrica & $\begin{array}{c}\text { Consequências no ser humano } \\
\text { Sensação de formigamento }\end{array}$ \\
\hline $1-10 \mathrm{~mA}$ & \begin{tabular}{c} 
Sensação dolorosa \\
\hline $10-20 \mathrm{~mA}$
\end{tabular} \\
\hline $10 \mathrm{~mA}<\mathrm{ou}<20 \mathrm{~mA}$ & $\begin{array}{c}\text { Dificuldades na respiração, que podem } \\
\text { causar morte por asfixia }\end{array}$ \\
\hline $100 \mathrm{~mA}>$ & Fibrilação cardíaca \\
\hline $200 \mathrm{~mA}>$ & Graves queimaduras e parada cardíaca \\
\hline $1 \mathrm{~A}>$ & $\begin{array}{c}\text { Queimaduras extremamente graves, necrose } \\
\text { dos tecidos, morte instantânea }\end{array}$ \\
\hline
\end{tabular}

Fonte: https://www.osetoreletrico.com.br/tipologia-dos-acidentes-eletricos-nobrasil.

Conforme Castro e Lima Júnior (2015) estudaram o perfil epidemiológico das vítimas de choque elétrico atendidas em um Centro de Tratamento de Queimados do Estado do Ceará. Em relação às vítimas, 91\% foram do sexo masculino e $9 \%$ do sexo feminino.

Os acidentes de trabalho foram responsáveis por $70 \%$ das internações, sendo que 64\% ocorreram na construção civil. Quanto ao tipo de trauma elétrico, 
$78 \%$ foram por passagem de corrente elétrica e $22 \%$ por arco voltaico. Em $87 \%$ dos casos, os pacientes apresentavam queimaduras profundas de terceiro grau.

Certamente os estudos em um estado de pequeno porte como o Ceará representam uma porcentagem ínfima do número real de acidentes desse tipo no Brasil.

\subsection{A UTILIZAÇÃO DOS EPIS}

O EPIS são os equipamentos que servirão para resguardar a saúde do trabalhador, prevenindo acidentes e/ou diminuindo os danos ocasionados por esses. Está previsto na legislação, mas ainda por conta da falta de utilização dos mesmos, são identificadas milhares de acidentes e ocorrências que poderiam ter menor impacto na vida do trabalhador caso as normas e regulamentos fossem cumpridas por ambos, empregadores e empregados.

Segundo Dobrovolsky (2008):

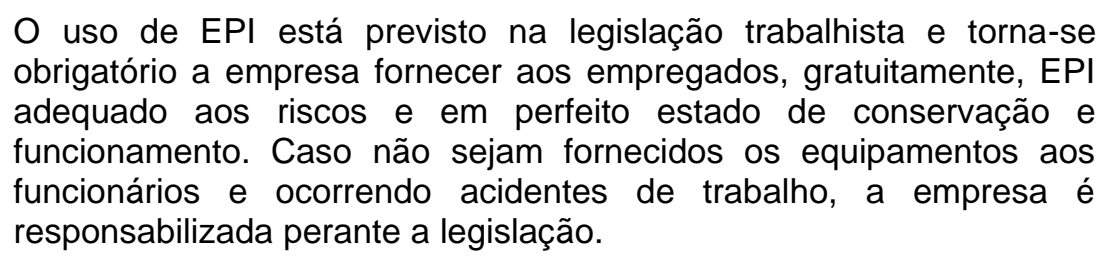

A NR6 considera as obrigações do empregador quanto ao fornecimento dos EPls e, mas destaca porém que os empregados devem ter a responsabilidade pelo seu uso, guarda e conservação dos mesmos.

\subsection{EM BUSCA DA CONSCIENTIZAÇÃO DO EMPREGADOR E DO EMPREGADO}

Ainda segundo Dobrovolsky (2008), é recente o campo de estudos acerca da utilização dos EPIS, porém o seu crescimento é paralelo aos números que se apresentam (conforme demonstrado nos quadros acima) das ocorrências no país. É preciso que haja uma conscientização tanto do empregado quanto do 
empregador para a utilização dos mesmos e para isso a autora ressalta a importância da Comissão Interna de Prevenção de Acidentes (CIPA) que deve existir em cada empresa como forma de garantir a segurança no ambiente de trabalho.

A NR5 dispõe que a CIPA tem como objetivos prevenir acidentes e doenças ocasionadas no ambiente do trabalho, assegurando a compatibilidade do trabalho com a preservação o da vida e a promoção da saúde do trabalhador. A atuação da CIPA torna-se fundamental para ajudar a melhorar as condições de segurança e higiene, além de prevenir doenças ocupacionais, como lesão por esforço repetitivo (LER), dores musculares, etc e consequentemente melhorar a produtividade na empresa. (DOBROVOLSKY, 2008).

Ainda segundo a mesma autora em pesquisas realizadas internamente por algumas empresas percebe-se certo descaso no cumprimento das normas tanto por parte do empregador, em relação a aquisição de equipamentos, tanto no caso do empregado com a resistência em utilizá-los (quando existem).

Reitera que nesses casos o item mais identificado para a não utilização desses é o desconforto que os mesmos provocam. Os principais motivos de desconforto foram identificados durante a sua utilização, dores de ouvido e coceira, calor, incômodo dos calçados, entre outros, o que indica despreparo, falta de costume por parte dos funcionários ou inadequação do próprio EPI. (DOBROVOLSKY, 2008).

\section{CONCLUSÃO}

Mesmo diante dos crescentes números dos acidentes de trabalho e embora haja o respaldo legal e constitucional para proteger o trabalhador no combate e prevenção a esses acidentes, observa-se que ainda há uma resistência na utilização de equipamentos de proteção individual (EPI) que assegurarão menores riscos de lesões graves e morte em caso de acidentes. 
Percebeu-se através da pesquisa que os dados recolhidos em termos de acidentes, previdência social, demonstram que ambos, empregador e empregado falham no item segurança uma vez que ambos são reticentes em relação à importância desses aspectos.

Conclui-se assim que, mais que a responsabilização legal para os empregadores, é necessário implantar programas de treinamento na empresa a fim de conscientizar empregados sobre a necessidade de utilização das EPIS a fim de resguardar sua saúde e sua vida; apoiar e incentivar as ações da CIPA a fim de que haja uma melhor supervisão e verificação dos pontos falhos e poder melhorar assim a produtividade ser colocar em risco à saúde do trabalhador. 


\section{REFERENCIAS}

AYRES, Dennis de Oliveira. Manual de Prevenção de Acidente do Trabalho. São Paulo: Editora Atlas, 2001.

D. O. Manual de prevenção de acidentes do trabalho: aspectos técnicos e legais/ Dennis de Oliveira Ayres, Jose Aldo Peixoto Corrêa. São Paulo: Atlas, 2001.

BOZZA. André Francisco. Segurança No Trabalho Através do uso de Epi's: Estudo De Caso Realizado Na Construção Civil De Santa Maria. 2010. https://acervodigital.ufpr.br/bitstream/handle/1884/34382/BOZZA,\%20ANDRE\% 20FRANCISCO.pdf?sequence $=1$

BRASIL. LEI № 8.213, DE 24 DE JULHO DE 1991. Disponível em https://www2.camara.leg.br/legin/fed/lei/1991/lei-8213-24-julho-1991-363650normaatualizada-pl.pdf Acesso em 30 de setembro de 2020.

BRASIL. Ministério Público do Trabalho. Observatório de Segurança e Saúde no Trabalho. Disponível em https://smartlabbr.org/sst. Acesso em novembro de 2020.

CASTRO, Ana Neile Pereira de; LIMA JÚNIOR, Edmar Maciel. Perfil epidemiológico de pacientes vítimas de choque elétrico em um hospital de referência em Fortaleza. Revista Brasileira de Queimaduras, Fortaleza, v. 1, n. 14, p.27-30, abr. 2015.

DUARTE, Francisco; THERY, Laurence; ULLILEN, Carolina. "Os equipamentos de proteção individual (EPI): Protetores, mas nem sempre": Apresentação do dossier. Laboreal, Porto, v. 12, n. 1, p. 9-11, jul. 2016. Disponível em <http://www.scielo.mec.pt/scielo.php?script=sci_arttext\&pid=S164652372016000100002\&lng=pt\&nrm=iso>. acessos em 15 nov. 2020. http://dx.doi.org/10.15667/laborealxii0116fd 
DOBROVOLSKY, Marlene et. al. Segurança no trabalho: uso de EPI. 4ํㅗ․ Encontro De Engenharia e Tecnologias em Campos Gerais. Disponível em http://www.4eetcg.uepg.br/oral/56_2.pdf acesso em 13 de novembro de 2020.

MANNRICH, Nelson. Inspeção do Trabalho. São Paulo: LTR Editora, 1991.

MARTINS, C L. Equipamentos de Proteção Individual: A Perspectiva de Trabalhadores que Sofreram Queimaduras no Trabalho. Rev Enferm UFSM 2013 3(Esp.): 668-678. Doi: 10.5902/2179769211060 Disponível em https://periodicos.ufsm.br/reufsm/article/viewFile/11060/pdf Acesso em 03 novembro de 2020.

MINISTÉRIO DO TRABALHO E DO EMPREGO. Normas Regulamentadoras. Disponível

em: <www.mte.gov.br>.

PEIXOTO, N.H. Segurança do Trabalho. Disponível em http://redeetec.mec.gov.br/images/stories/pdf/eixo_ctrl_proc_indust/tec_autom_ ind/seg_trab/161012_seg_do_trab.pdf

SOUZA, Ellen Lucy Vale de et al. Uso dos equipamentos de proteção individual em unidade de terapia intensiva. Rev. Enf. Ref., Coimbra, v. serlll, n. 4, p. 125133, jul. 2011.Disponível em <http://www.scielo.mec.pt/scielo.php?script=sci_arttext\&pid=S087402832011000200013\&lng=pt\&nrm=iso > . acessos em 15 nov. 2020.

TORREIRA, Raúl Peragallo. Manual de Segurança Industrial. São Paulo: Margus

Publicações, 1999.

https://www.osetoreletrico.com.br/tipologia-dos-acidentes-eletricos-nobrasil/\#: :text=sa\%C3\%BAde\%20das\%20pessoas.- 
,Em\%20servi\%C3\%A7os\%20com\%20eletricidade\%2C\%200\%20trabalhador\% 20 est\%C3\%A1\%20exposto\%20a\%20riscos,de\%20origem\%20el\%C3\%A9trica $\% 2 \mathrm{C} \% 20$ queimaduras\%20etc. 